\title{
Games of Inquiry for Collaborative Concept Structuring
}

\author{
Mary A. Keeler ${ }^{1}$ and Heather D. Pfeiffer ${ }^{2}$ \\ ${ }^{1}$ Center for Advanced Research Technology in the Arts and Humanities \\ University of Washington, Seattle, Washington 98117, USA \\ mkeeler@u.washington.edu \\ ${ }^{2}$ Department of Computer Science \\ New Mexico State University, Las Cruces, New Mexico 88003-8001, USA \\ hdp@cs.nmsu.edu
}

\begin{abstract}
Google's project to digitize five of the world's greatest libraries will dramatically extend their search engine reach in the future. Current search-engine philosophy, which asserts that "any search starts with a question to be answered," will need to be advanced in terms of Peirce's philosophy: "Any inquiry begins by creating an hypothesis to be tested or with abduction." As conceptual structures researchers prepare to meet access challenges in the world of large Internet knowledge stores, they have a solid foundation in Peirce's theorized stages of inquiry: abduction, deduction, and induction. To indicate how conceptual structures tools must augment collaborative, Internet-based inquiry, we imagine a future scenario in the context of a user-centered testbed, where Peirce scholars apply Peirce's pragmatic theory in their complex manuscript reconstruction work. We suggest that games of inquiry can be developed to formalize user collaboration and technology needs, for improved specification of tool requirements in the testbed context.
\end{abstract}

\section{Scenario Context and Characters}

Imagine some particular day in the future, when the technology to support collaborative inquiry has advanced through rapid-prototyping in user-centered testbeds, so that researchers can work together efficiently, no matter where they are located and no matter where their primary data is safely stored in library archives. In this particular scenario, the researchers are Peirce scholars and the data of their research are Peirce's manuscripts archived at Harvard's Houghton Library. These scholars are remotely located from one another, so must use the Internet to collaborate in their work to transcribe the digitized images of Peirce's handwritten manuscripts into digital text and to catalog a coherent sequence of Peirce's manuscript pages. Transcription involves deciphering what Peirce wrote, which becomes more difficult as his handwriting deteriorated in his declining years when he suffered from cancer and other ailments.

During the last seventeen years of his life (1897-1914), Peirce produced his most intensive theoretical work, on semiotic, pragmatism, and his system of Existential Graphs (EG) as a notation for the study of logic [see 1 and 2]. Amounting to some 
40,000 pages, very few of these manuscripts have ever been published. And very few scholars have ever studied these pages, which their Houghton Library curator estimates will survive no more than a few dozen more years (due to their high-acid paper). By 2005, scholars and technologists realized that Internet-based technology had advanced to make possible the reconstruction and representation of Peirce's polymathic corpus (ranging from religion, philosophy, and cosmology, to computer science, mathematics, logic, geophysics, and many others fields). Five, especially qualified scholars joined to pursue some of that reconstruction, collaboratively, in the Peirce Online Resource Testbed (PORT) project [3].

Jay Zeman, Professor Emeritus of Philosophy and specialist in Peirce's EG, lives in Florida; Bob Burch, Professor of Philosophy at Texas A\&M is also an expert in Peirce's EG; Peter Øhrstrøm, Professor of Communication at the University of Aalborg in Denmark is an specialist in modal logic (including Peirce's "gamma graphs"); Robert Marty is Professor Emeritus at the University of Perpignon in France, a specialist in Peirce's "semiotic logic"; and Frithjof Dau, in Germany, completed his doctoral degree studying concept graphs in 2002, and a treatise on Peirce's EG in 2005. They joined PORT's collaboratory testbed, in partnership with technologists, to help develop imaging and transcribing methods and tools that would improve the quality and efficiency of their work. They are particularly motivated to create better access to the manuscript data because of inadequacies and misrepresentations in previous editions of Peirce's writings. The Collected Papers of Charles Sanders Peirce (referred to as " $C P^{\prime \prime}$ ), an eight-volume edition produced more than fifty years ago ${ }^{1}$, remains (in spite of its many deficiencies) the most complete print resource of his work ${ }^{2}$.

On this particular imaginary day in the future, the scholars are engaged in perhaps the most difficult detective problem during the initial stage of

\footnotetext{
1 The misnamed Collected Papers of Charles Sanders Peirce is the only large-scale and purportedly comprehensive edition of Peirce's writings. Published in six volumes, from 1931 to 1935 , and enlarged by two volumes in 1958, its topical selections omit Peirce's writings on science and mathematics almost entirely. Although, it contains nearly 150 selections from his unpublished manuscripts, only one-fifth of those selections consist of complete manuscripts, and many of them are inaccurately dated; parts of some manuscripts appear in up to three of the eight volumes, and at least one series of papers is scattered throughout seven of the eight. Most manuscripts appear in excerpts (with only rare indication of how much has been left out), and different parts of the same manuscript appear in different volumes (because of the topical order), and in some cases parts of different manuscripts are grafted together (without mention), sometimes consisting of writings composed more than three decades apart. As a scholarly tool, this edition is unreliable and often frustrating [See 4 for detailed discussion].

2 A textually and chronologically reliable print edition of Peirce's writings was begun in the late 1980s (Writings of Charles S. Peirce: A Chronological Edition) [5]. As of 2005, only six of the originally projected thirty volumes have been published, and even if completed, that edition would present less than one-third of Peirce's entire work. More significantly, in its paper-print format, cost of production may prohibit representation of Peirce's late manuscripts, which are characterized by text enclosed in graphical figures, graphics embedded in text, text contoured around graphics, whole pages of graphics with no text at all, and graphical figures with as many as four colors.
} 
reconstructing Peirce's corpus. As in the initial stage of scientific investigations, the scholars must prepare the raw data (in the form of digitized manuscript page images) to serve as reliable data for interpretation, by calibrating (ordering the pages in some sequence and grouping the sequences accurately). For scholarly interpretation of his ideas as they evolved, the page order should be chronological, as they were written by Peirce. Unfortunately, achieving that ideal may never be entirely possible, since only about one third of the corpus was originally dated by Peirce. At least, the order of each manuscript should be as close to Peirce's own apparent compositional order as possible. Even that goal is challenging, since some 10,000 pages in the Harvard collection ${ }^{3}$ are considered "lost." These pages are present in the collection, but not properly placed in any manuscript sequence. Many more pages have been tentatively placed in supplementary folders, and labeled, for example, "145(s)," to indicate pages thought to belong to MS 145. In other cases, if scholars have not yet considered some group of "lost pages," which seem to belong together, they are simply labeled with a manuscript number. Such is the case with manuscript "507," a folder of nine pages, listed in the "Robin catalogue" of the Houghton collection ${ }^{4}$ as undated and unnumbered.

\section{A Manuscript Mystery}

We enter the scenario with the five scholars attempting to solve a "lost page" mystery, as an example of the complexity of work in the initial stage of reconstruction. The 32 pages of the folder labeled "145(s)" have been previously identified as possibly belonging with the folder labeled "145," which the Robin catalogue lists as a manuscript of 12 pages (undated and unnumbered). Quoting from the manuscript title page, the catalogue entry reads: "An Attempt to state systematically the Doctrine of the Census in Geometrical Topics or Topical Geometry, more commonly called 'Topologie' in German books; Being a Mathematical-Logical Recreation of C.S. Peirce following the lead of J.B. Listing's paper in the 'Gottinger Abhandlungen'" [6:17]. The scholars each verify this catalogue entry with what they find in the "145" folder (using Hoffmann's online version of the Robin catalogue and PORT's online manuscript data archive). They find that the association of "145" pages with the manuscript pages of "145(s)" is

\footnotetext{
3 When Peirce's papers (amounting to between eighty and one-hundred thousand pages) were given to Harvard, shortly after his death (1915), they were not properly stored for several years (apparently, even distributed as scratch paper in war-time paper shortages), during which they fell into disarray. The microfilm (high-contrast, black and white, produced in 1967) and photo copies from it cannot be used in place of the original pages, which must be carefully examined for any discriminating features that might be clues as to where they belong (such as color and width of ruled lines and handwritten script, type of paper, watermark, shape of a torn or cut edges, weathering effects, and so on).

4 Richard Robin's Annotated Catalogue of the Papers of Charles S. Peirce [6] provides the most valuable and comprehensive view of the disordered manuscripts (and their incomplete representation in the microfilm edition). See Michael Hoffmann's digital version of the Robin catalogue: http://www.iupui.edu/ peirce/robin/robin.htm.
} 
supported by empirical evidence they can see in the manuscript page images displayed on each of their screens simultaneously. The pages of "145" are in a notebook with lined pages that appear to match the pages of "145(s)." But they question whether the folder labeled "145(s)" (of 32 pages) should be designated "145," while the folder labeled "145" (of 12 pages) should be "145(s)," indicating that its fewer pages are supplementary material for what should be the primary material in the folder currently marked "145(s)"?

Meanwhile, at least one page in the "507" folder (of unplaced pages) has been recognized as very similar in appearance and content to page number 22 in "145" (so close as to be considered possibly an earlier or later-written version of page 22). However, even though the "507" page has obviously been cut from a notebook, its cut edge does not match any cut fragment in the "145" or "145(s)" notebooks. And though its textual content appears to be nearly identical to that on page 22, the EGs across the top of the page are not identical. The "507" catalogue entry gives almost no clue: "Beta and gamma graphs, with algebraic translations. Rules of transformation" [6: 65].

Previously, the scholars had encountered the comparable case of a notebook catalogued and labeled as "464" and a folder of 15 pages labeled "464(s)" on notebook paper that looks exactly like that of the 35 pages of "464." In this case too, "464," but not "464(s)," has an entry in the Robin catalogue designating it as "Part 1 of the 3rd draft of 3rd Lecture" of his 1903 "Lowell Lecture" series.

As with "145," the content of one page of "464(s)" has obviously been cut from a notebook, and it appears very similar to that of a page in the "464" notebook; but in this case the cut edge of the "464(s)" page matches exactly with a cut fragment in "464," and even the marginal text that has been cut through matches. So there is strong empirical evidence that "464" and "464(s)" belong together, while the proper designation of "145" and "145(s)," together with the mystery of the "507" page (which is extremely similar in content but does not empirically match page 22 in "145"), remains in doubt. Where does this page belong, and how should "145" and "145(s)" be properly designated in the catalogue of manuscript material?

\section{Essential Collaboration Capabilities}

For the critical identification work in our future scenario of scholars at work, the digital images of the manuscript pages must be extremely accurate representations of the original pages. They must provide evidence not only of what Peirce rendered in graphical forms and in handwritten text but also of other bibliographic features (such as color, kind, and condition of the paper). The manuscript images must exhibit to all collaborating scholars the same critical features, no matter what may be the variations among the qualities of their computer display systems. Any visible feature on a page may be needed in their judgments as to where the page belongs, what was its significance to Peirce, and what insights it might convey. The mediating tools of their virtual collaboration context make it possible for the scholars to confer effectively in such minute judgments, in spite of the differences in display capabilities among their computer systems. 


\subsection{Consistent Image Quality}

An image-display mediator (originally developed as "AI-Trader," by Puder and Römer [7]), monitors the differences among the scholars' five different computer displays and matches them across all system factors (such as file-compression ratio, screen size and resolution, and color calibration). This automatically standardized image is the reference quality for all collaborators, and enables the mediator to notify the scholars when their views do not correspond. On request, the mediator negotiates among the collaborator's individual requests to establish the optimum perceived attribute values for any selected purpose. Matching views is especially important for collaboration on detailed features such as tone of paper (for page matching). Subtle qualities that are not immediately recognized as significant might be identified as crucial evidence by one scholar and then confirmed in collaborative interpretation. All scholars have access to reliably comparable views of the same artifact, while individually each is able to explore the primary data for potentially relevant features identified from the perspective of his particular background knowledge of Peirce's work.

The mediation service avoids the problem of simply serving the lowest display system capabilities, and allows the scholars to intervene in the process at any point needed to resolve discrepancies because of differences in image quality among their displayed views of manuscript pages. The lowest quality display system of any scholar does not prevent those with higher quality systems from seeking and finding crucial evidence, and bringing it to the collaboration context as the object for consideration and discussion. The image-display mediator negotiates among complexly interrelated system variance factors (including resolution and color accuracy, compressed file quality, and speed of transmission) to serve all participants efficiently. Concurrently, the scholars can readily monitor this mediation process, as it reconciles "competing factors," to remain aware in viewing the images as the evidence of what Peirce rendered on paper. Any relative bibliographic invariance they identify in the evidence (such as a particular type of notebook paper or color of ink used in particular graphic forms) might then serve to establish meaningful segmentation, to be indexed for catalogue identifications that can be used in automatically searching for possible matching pages.

\subsection{Concurrent Catalogue Documentation}

PORT's concept-based catalogue for the Peirce archive, which has evolved from the data of print finding aids, has been digitally linked to both transcribed text and digital images of the original manuscript pages. By means of the catalogue, each manuscript page's digital image and transcription is coded to all existent corresponding print edition entries of its content, and each image appears on screen with its actual or estimated date of composition, if known. The scholars can propose corrections to the catalogue entries reflecting any additions and alterations accumulated during their intensive transcription and calibration work. Variations among their transcriptions and calibrations are monitored automatically, by digital 
matching, and these points of disagreement are highlighted in the digital transcriptions.

An ontology of the collection (or a comprehensive framework capable of relating the digitized archive data in a conceptual structure, for logical representation of inference relations) interrelates the catalogue entries on many conceptual levels. Special ontologies function as specialized database indexes (or views), representing the conceptual perspectives of particular disciplinary conventions with respect to the archive and any related data. These specialized indexes continue to evolve as each discipline evolves, keeping all views conceptually coordinated. Formal Concept Analysis [see 8] provides a graphical interface of lattices displaying the related views of catalogue entries in a relational database [see 9]. Graphical views (or visualizations) of this data-under-evolution enable disciplinary specialists to remain critically aware of the complex implications of each researcher's contribution (including their own) with respect to others in the scheme of inquiry as a whole. Other methods of knowledge representation and processing have made possible the essential functions of this collaborative resource evolution (see section 5 for scenario examples of the user-driven development process).

\subsection{Essential Testbed Functions}

Scholars or researchers in any specific discipline can report their reconstructions of Peirce's complex arguments, as hypotheses, based on their interpretations of the imaged and transcribed manuscript content. Editors and other scholars or researchers are then able to track their own hypotheses as well as those of others, from the image evidence supporting them, through the systematic deduction of their implications for manuscript order and content, to the ongoing inductive testing by scholars or researchers who interpret and employ content of the reconstructed arguments. Not only is the order of pages in a manuscript frequently hypothetical because of lost or misplaced pages, but Peirce's complex style of composition increases the uncertainty of accurate reconstruction. He sometimes uses the same page in several versions of elaborated discussion, the course of which sometimes even doubles-back on itself to pick up an unexplored path.

In our future scenario, each scholar in the testbed creates a map of the page-bypage course of a particular hypothetical Peircean "exploration." These computergenerated diagrams record each (possibly unique) reconstruction of Peirce's multipath arguments ${ }^{5}$. These "S-diagrams" can then be matched, by either human perception or computer-generated graph methods. Detected relative invariance among maps reveals agreements in sequence across all scholars' hypothetical reconstructions, and pin-points where controversies in reconstructions lie and further investigation should be pursued. As interpretations proceed and scholars' hypothetical reconstructions evolve, a "dynamic map" is generated, which continues to display the evolution of the collaborative effort (see section 5). Many tools (for

5 As early as 1986, one Peirce scholar (Shea Zellweger) mapped on paper the pattern of several Peirce manuscripts, creating an elaborate, page-by-page, "organic" figure of the course of his writings (see 1 for examples). 
database, document, and knowledge-based management, search and retrieval, knowledge acquisition, interlingua for both natural language translation and system integration, knowledge-based communication services support and discourse management) have been integrated and customized to serve the scholars' reporting, tracking, and mapping needs (de Moor suggests an architecture [10:269-70]).

\section{Stages of Inquiry}

As our scenario proceeds, the scholars are engaged in hypothetical inference, the first stage of inquiry as Peirce conceived its three stages of abduction, deduction, and induction. In the first stage, abduction:

1. they experience a mysterious or disturbing phenomenon $(\mathrm{P})$ : that page 1 of manuscript "507" looks strikingly similar in content to but does not empirically match page 22 of manuscript "145(s)";

2. they suppose that $P$ would be explicable as not surprising, if hypothetical condition $(\mathrm{H})$ were true, and then;

3. they accept in these conditional terms that $\mathrm{H}$ might be true [see $C P$ 5.189].

Using the facts observable in the manuscript evidence, together with previous known facts of Peirce's work, each scholar attempts to formulate an $\mathrm{H}$ to explain $\mathrm{P}$. Abduction's role in inquiry is to begin argumentation by providing claims that suggest how further inquiry might proceed and what might be its aim. Peirce stresses its significance in relation to the other two stages of inquiry: "Its only justification is that from its suggestion deduction can draw a prediction which can be tested by induction, and that, if we are ever to learn anything or to understand phenomena at all, it must be by abduction that this is to be brought about" [CP: 5.171].

\subsection{Collaborative Abduction}

In the scenario, Jay Zeman studies his S-diagram for manuscript "145" and notices that the content of the questionable "507" page might indicate a "branch" in Peirce's argument toward a discussion of gamma graphs, which could connect with the content of "145(s)" at page 22. He uses mediated standard-quality images to refer to both pages, together, indicating to the other scholars on an overlaid commentary image file what passages and points on the pages of text and images lead him to make his conjecture. Meanwhile, Bob Burch has been comparing the image of the "507" page with images of "145(s)" and "145" pages, arranging them side-by-side on his display screen. Since all the manuscript material was imaged at a standard focal length, the pages of each folder are represented in actual size relationships. Bob finds that the "507" page matches the "145(s)" paper (in terms of size and ruled line spacing), and appears to match that of "145." He double-checks the match of paper tones with a color-calibrated detector and finds that they apparently measure the same color; but to be certain, he runs a test on the full-size image files (with 
more color-depth data than can be displayed on his screen). That test indicates that the "507" paper is the same as the "145," but not quite the same as that of "145(s)."

Peter Øhrstrøm is working on the content alone, and finds that the folder labeled "145(s)" picks up the topic of "145" soon after the first page, and that the second page has a verso with only gamma graphs, possibly indicating where Peirce could have made a branch in his trend of thought. Peter reports that hypothesis, and Frithjof Dau confirms it as plausible from his knowledge of Peirce's EG notation (alpha, beta, and gamma). Frithjof's analysis of why Peirce created the "507" page indicates that he apparently redrew the EGs of "507" on the "145(s)" page 22, leaving out one figure, but Frithjof is not entirely sure that "507" is a bridge between "145" and "145(s)." Meanwhile, Robert Marty wonders (based on his knowledge of Peirce's semeotic logic) if the "507" page may have been cut from some as yet undiscovered version of "145," because Peirce decided it simply headed too quickly into the gamma graph part of EG, without explaining significant sign theory context. Although Marty suspects, he is not yet ready to assert that conjecture formally as an hypothesis, and must consult some of Peirce's other discussions of his logic and its graphical notation.

Jay Zeman mentions some significant bibliographic evidence, at this point: that "145(s)" has a title page very similar to that of "145," although with fewer colors in its title lettering and a shorter title, "Geometrical Topics;" and it is dated "April May 1905." If Peirce wrote this manuscript over a month's time, that might explain the slight difference found between its tone of paper and that of "145"? Could the fact that "145(s)" has fewer colors throughout its 32 pages (only green, blue, and black) indicate it was Peirce's first attempt, while the five colors (green, blue, red, brown, and black) of "145" indicate a more advanced, succeeding attempt? As Jay closely compares the images of pages from both on his screen, he finds that "145" is definitely more elaborate in content, with both colorful text and graphics. The mystery remains, where does the "507" page then belong?

\subsection{Directing Inquiry}

Abduction refers to any operations by which theories and concepts are engendered [see CP 5.590 (1903)]. As inquiry proceeds, the consequences (or implications) of each scholar's hypothesis must be traced out by deduction, and compared with the results of experimentation by induction (in further efforts to represent his corpus accurately and, beyond, in the interpretation of Peirce's ideas in the many fields where it is relevant, including knowledge representation). As soon as one hypothesis is refuted, another one is subjected to the same stages of argumentation: Abduction merely suggests what may be; Deduction proves what must be; Induction shows what actually is operative [see $C P$ 5.590]. Peirce identifies other modes of reasoning that mingle these three forms of argument [see CP 2.103 (1902)], for example, analogy [see CP 7.97 (1902); also see Sowa's discussion of analogy as a prerequisite for logical reasoning: 11], but he considers these three to be logically elementary, with distinct roles and limitations. 
Abduction furnishes all our ideas concerning real things, beyond what are given in perception, but is mere conjecture, without probative force. Deduction is certain but relates only to ideal objects. Induction gives us the only approach to certainty concerning the real that we can have. In forty years diligent study of arguments, I have never found one which did not consist of those elements. [CP 8.209 (1905)]

Peirce criticizes the common mistake of mixing the three as a simple argument, and even more commonly of confusing abduction with induction. They are "opposite poles of reason": one the most ineffective argument, the other the most effective.

The method of either is the very reverse of the other's. Abduction makes its start from the facts, without, at the outset, having any particular theory in view, though it is motivated by the feeling that a theory is needed to explain the surprising facts. Induction makes its start from an hypothesis, which seems to recommend itself, without at the outset having any particular facts in view, though it feels the need of facts to support the theory. Abduction seeks a theory. Induction seeks for facts. In abduction the consideration of the facts suggests the hypothesis. In induction the study of the hypothesis suggests the experiments which bring to light the very facts to which the hypothesis had pointed. [CP 7.218 (1901)]

Induction (the experimental testing of a theory) is the most effective because, "although the conclusion at any stage of the investigation may be more or less erroneous, yet the further application of the same method must correct the error." Induction measures the degree of concordance of theory with fact $[C P 5.145$ (1903)].

Peirce conceived his theory of inquiry to explain the "marvelous self-correcting property of reason," and how "making experiments" upon his logical graphs can come into play [CP 5.579 (1898); and see Dau's analysis of Peirce's EG: 12]. After abduction allows a mass of facts to suggest a theory, deduction constructs an image or diagram of that suggested ideal interpretation by which relations of parts that are implicit in the proposed theory become explicit and convincingly predictable. Induction then tests to verify that predictability under real conditions. One of his latest accounts stresses the directive nature of inquiry.

Abduction having suggested a theory, we employ deduction to deduce from that ideal theory a promiscuous variety of consequences to the effect that if we perform certain acts, we shall find ourselves confronted with certain experiences. We then proceed to try these experiments, and if the predictions of the theory are verified, we have a proportionate confidence that the experiments that remain to be tried will confirm the theory. [CP 8.209 (1905)]

In inquiry, we ask the pragmatic question: If what we conjecture were true, as the cause of something unexpected, what would be the consequences? We conjecture what might have been the antecedents from the consequences we observe, provisionally accept that explanation as an hypothesis worth testing, then proceed to the deductive stage of observing what we have asserted as the state of things, in diagrams (or graphs) of its premises. We can then perceive in the parts of the diagram relations not explicitly mentioned in the premises, as implications that should subsist, at least in a certain proportion of cases, and conclude their necessary 
or probable truth [see $C P 1.66$ (c. 1896)]. Abduction and deduction establish the rational directions for inductive investigation [see 13, for a detailed analysis verifying the order of these stages].

\section{Games of Inquiry}

We can correlate Peirce's theory and logical stages of inquiry with Robert Brandom's pragmatic inferentialist theoretical framework and his model of discursive practice [see 14], for a functional analysis of the scenario. Under that model, when a scholar asserts a claim (an hypothesis) about the manuscript pages, he expresses his commitment to a belief, which gives its conceptual content his authority and licenses others (including himself) to undertake a corresponding commitment to use that assertion as a premise in further inferences. In Brandom's theory, inferences involve both intercontent and interpersonal relations in the discursive practice of "giving and asking for reasons." When one scholar expresses a claim that entails a claim expressed by another, anyone who is thereby committed to the first is committed to the second. In Brandom's model, the direction and strength of any scholar's assertion (of its conceptual content) are defined by two normative dimensions: a speaker's commitment to that content, and what serves as entitlement to (as reasons for) that commitment. Communication becomes essential to rational practice, as "the interpersonal, intracontent inheritance of entitlement to commitments" [15:165].

Pragmatically, Brandom and Peirce agree that logic is "the linguistic organ of semantic self-consciousness and self-control," making it possible "to criticize, control and improve our concepts" [15:19, 149]. Logic's instrumental task is to make explicit what is implicit in the use of ordinary vocabulary, to reveal patterns of inference that are formally valid because they are invariant. But Brandom emphasizes that these formal properties of inference derive from material inferences that must be explained in terms of ordinary language; so the primary task of logic is to help us express something about the conceptual contents of material inferences. Rather than a standard of right reasoning, logic is "a 'distinctive set of tools' which we can use to make explicit (and hence available for criticism and transformation) the inferential commitments that govern the use of all our vocabulary, and hence the contents of concepts" [15:30; 14:246-6]. Consistent with Peirce's pragmatic theory, Brandom warns that when we display relevant grounds and consequences in logic to assert their inferential relations, we must never expect to achieve complete transparency of commitment and entitlement. That ideal serves as only a conceptual limit to hope for in pursuing inquiry [see 15:149, 76].

Brandom's functional theory of concepts focuses on their role in reasoning as prior to their supposed origin in experience [see 15:25;14:243]. Conceptual content is determined by how concepts are structured by inferences, prior to their use in effectively referring to anything. He stresses: "the representational aspect of the propositional contents that play the inferential roles of premise and conclusion should be understood in terms of the social or dialogical dimension of communicating reasons, of assessing the significance of reasons offered by others," 
rather than as arrived at noninferentially from sense perception [see 15:166]. His model of discursive practice treats concepts as norms, not as single signs but as nodes in an inferential network of related concepts. Those norms determine "what counts as a reason for particular beliefs, claims, and intentions," as rules determine the correctness of moves in a game $[15: 25 ; 14: 243]^{6}$. In fact, Brandom's model identifies conceptual content in an expression by whether it can play a role in the inferential game of making claims and giving and asking for reasons ${ }^{7}$.

Brandom contends that we give beliefs, desires, and intentions conceptual content when we ask such pragmatic questions as "under what circumstances would what is believed, desired, or intended be true?" [15:158]. His theory and model enforce the distinction between what is said or thought (the propositional dimension) and what it is said or thought about (the representational dimension), and he stresses that even our reports of observable properties, such as color, must be inferentially articulated to have conceptual content. Otherwise, we could not distinguish these noninferential reports from the automatic responses of machinery, such as thermostats and photocells. To understand a concept is to be able (or know how) to distinguish what follows from its application and what it follows from in the practical sense [see 15:108]. Any expressed report that functions conceptually must at least serve as a premise from which to draw inferential consequences: there can be no autonomous language game of entirely noninferential reports. The representational use of propositional concepts relies on the social structure of their inferential articulations in the game of giving and asking for reasons [see 15:183]. Conceptual content is collaborative, inferential content.

\subsection{The Manuscript Reconstruction Game}

The scholars in the scenario report their claims in conditional form, to make explicit what is not otherwise made explicit in their ordinary discourse involving the informal material inferences that reflect what they consider significant during their empirical observations of the manuscript material. Using these formal expressions (or asserted hypotheses), they engage in collaborative discourse. In the testbed context [see 16], the game mode of discourse helps the scholars formulate and select valid hypotheses to explain their surprising experience of the evidence (the mystery of the "507" page). Their game, called the Manuscript Reconstruction Game (MRG), is played as a formal deductive and inductive test of each scholar's proposed hypothesis (of its strength in terms of commitments and entitlements as rationally and empirically valid for accurately reconstructing the manuscript pages).

Those playing the game must report: by selecting propositionally contentful expressions capable of serving in inferences as both premise and conclusion (what can be offered as, and itself stand in need of, reasons). Learning to play the game involves being able to tell what is a reason for what, distinguishing good reasons

6 Peirce stresses a similar semeotic understanding in indicating how his Existential Graphs should be applied dialogically in inquiry (see $C P$ 4.429-431).

7 Brandom's model is based on Wilfred Sellars's suggested game of "giving and asking for reasons" [see 15:35; and 14:251-54]. 
from bad, by keeping score on what other players are committed and entitled to, as two dimensions of normative status. Understanding the conceptual content of a claim is being able to accord it proper significance, or knowing how a commitment would change the score in various inferential contexts with other claims [see 15:165-66]. So the players must also track the relations of commitments and entitlements in the game's progression.

If Bob Burch makes a commitment by expressing the declarative sentence: "The paper of page 1 of manuscript '507' does not match that of page 22 in '145(s)' (with the color match test results as entitlement), indicating it was not originally written in that notebook," then a commitment by Jay Zeman, such as, "Manuscript '507' was cut from '145(s)'," is not compatible. And other possible sentences uttered by the other scholars may be incompatible. For each scholar's explicitly expressed observation, there will be a set of sentences that are logically incompatible with it; and inclusion relations among the sets of sentences asserted in a dialog among the five scholars will then indicate inferential relations among the sentences. That is, for example, the content of the claim expressed by asserting, "Page 1 of '507' could mark a branch of ' 145 '," entails the content of the claim expressed by asserting, "'507' is the same paper tone as ' 145 '," because everything incompatible with being the same paper tone is incompatible with marking a branch of "145"-perhaps. The two sorts of normative status (commitments and entitlements) and their interactions among the sentences asserted in the play of the game, are tracked in the three sorts of inferential relations:

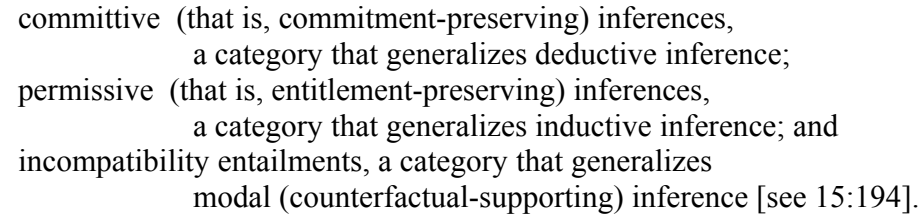

The incompatibilities among commitments and their entitlements are automatically displayed to the scholars for their examination and consideration.

The three sorts of inferential consequence relations are ranked (all incompatibility entailments are commitment-preserving, though not vice versa, and all commitment-preserving inferences are entitlement preserving, though not vice versa) [see 15:195]), and can be used to map the discussion's evolution as the scholars produce and consume reasons. Inheritance of commitment, inheritance of entitlement, and entailments according to the incompatibilities defined by the interactions of commitments and entitlements compose three axes that "inferentially articulate." The map reveals what Brandom calls the normative fine structure of rationality (NFS), describing the progress of the game in making implicit content explicit [see 15:195; also see Wille's rendering of Brandom's "rich inference structures" in Contextual Judgment Logic: 17]. The scholars rely on the mechanism of the game, as a logical editor or "logical lens," to help them focus on and clarify the complexities of inference and conceptual content in their collaborative view of the manuscript evidence. Incompatibilities that emerge mark possibly missing hypothetical inferences that should direct further inquiry. Meanwhile commitment- 
preserving inferences trace the implications of validly related claims, and entitlement-preserving inferences record the tested reliability of those claims with respect to the evidence.

Under Brandom's framework, each scholar's commitments are his beliefs and the entitlements are his reasons for believing, based on the evidence. They express these commitments and entitlements to make explicit their implicit material inferences in an "inferentially articulated network," as the game requires. The game offers a method of "harmonizing" these rational and empirical elements of their collaborative conceptual content, by directing attention to incompatibilities to be resolved. In attempting to maximize their own scores, players must minimize the incompatibility entailments to improve their collaborative hypotheses, as the ultimate objective of the game. Brandom compares that process to judges formulating principles of common law: "intended both to codify prior practice, as represented by precedent, expressing explicitly as a rule what was implicit therein, and to have regulative authority for subsequent practice" [15: 75-76; and see 11:19]. Peirce's theory of inquiry has the same normative aim: "to articulate the conditions for veracity, under which thinking can reasonably be considered to increase order, harmony, and connectedness in the world of thought" [18:35; see 14:256].

\subsection{The Tools Improvement Game}

In the scenario, Peter Øhrstrøm, Robert Marty, and Frithjof Dau need to find more material evidence in the manuscript collection from which to determine their asserted commitments that are based on valid entitlements. They begin a game with conceptual structures tools builders to specify requirements for an automated method of finding all instances of Peirce's gamma graph work in the archive. Selecting Martin's WebKB search engine [19], for testing, they first attempt to locate all manuscripts where Peirce discusses both his sign theory and his EG together. The same harmonizing framework helps the scholars jointly clarify their collaboration tool requirements in their testbed partnerships with tool developers, by making explicit their implicit augmentation-tool needs ${ }^{8}$. Emerging requirements can be tracked to eliminate incompatibilities, and an NSF concept map is generated as a virtual prototype (or hypothetical tool) for evaluation, before any actual system is built. Testing the actual prototype is carried out in the same recursive process of inquiry, with the scholars now playing the game as they assess their needs in using it; and each prototype generation is tracked to eliminate (or make compliant) incompatibilities with other tools. The NFS map represents each tool system's evolving documentation, and reveals incompatibilities among tool specifications to aid in developing standardization that is directed de jure by tool usage, rather than de facto, by tool developers. The "tools improvement game" (TIG; to be described in future work) can be played concurrently with the MRG.

8 See http://port.semanticweb.org/ICCS2005/gametools.pdf for a diagram indicating how the tools operations can be connected and communicate with other components of the testbed. John Sowa's Flexible Modular Framework (FMF) [20] and Heather Pfeiffer's Conceptual Programming Environment (CPE) [21] integrate the tools and data needed in the testbed. 


\section{Conclusions}

In 1868, Peirce began his study of inquiry with an essay intended for a series called "Search for a Method." He began by contending that in some or all respects our "modern minds" still operate under Cartesian influence when we assume that argumentation is represented by "a single thread of inference depending often upon inconspicuous premisses." Peirce urged that we should "stand upon a very different platform from this." We must begin inquiry with all the prejudices we actually have that are based on valid entitlements: "no one who follows the Cartesian method will ever be satisfied until he has formally recovered all those beliefs which in form he has given up" [CP 2.265]. And because of those beliefs: "all higher animals have some insight into what is passing in the minds of their fellows. Man shows a remarkable faculty for guessing at that. Its full powers are only brought out under critical circumstances" [CP 7.40]. In the course of inquiry, we may find reason to doubt what we began by believing; but in that case we doubt because we have a positive reason for it, not because we began with complete doubt.

Brandom's inferentialist model gives Peirce's pragmatic theory of inquiry the functional context of a game. In asserting sentences, we explicitly undertake commitments to the correctness of our material inferences (our implicit beliefs) from the circumstances to the consequences of their application. In making these commitments, we understand propositional content, "not as the turning on of a Cartesian light, but in practical mastery of inferentially articulated responses." Clear thinking and expression are matters of knowing what we are committed to in making claims, and what entitles us to those commitments. If we fail in either of these components, we fail to understand conceptual content, because we fail to grasp the inferential commitments that our use of concepts involves [see 15:63-64; 14:252-53]. Although Brandom's model obscures the initial significance of abduction that Peirce emphasizes in ordering the three stages of inquiry, Brandom clearly incorporates it as a directing influence in the recursive process of conducting inquiry, which is functionally consistent with Peirce's theory [see 14:255-57].

Whether we hope to reconstruct manuscripts or to improve conceptual structures tools, Brandom's model and Peirce's theory of inquiry promise a solid foundation for meeting the challenges of Google's "digital library of the 21st century." This paper attempts to take its own pragmatic advice: Before entering inquiry, we should mark out the proposed course of it, even if circumstances subsequently require the plan to be modified, as they usually will [see $C P$ 5.34]. Pragmatically, our scenario offers an abduction, from which we may deduce what would be the necessary specific tool requirements, for that hypothetical concept of collaborative scholarship to become true. 


\section{References}

General Notes: "MS" references are to Peirce's manuscripts archived at the Houghton Library, Harvard; for $C P$ references, Collected Papers of Charles Sanders Peirce, 8 vols., ed. Arthur W. Burks, Charles Hartshorne, and Paul Weiss (Cambridge: Harvard University Press, 1931-58).

1. Keeler, M. [2003]. "Hegel in a Strange Costume: Reconsidering Normative Science in Conceptual Structures Research." In: de Moor, A., Lex, W., and Ganter, B. (Eds.): Lecture Notes in Artificial Intelligence, Vol. 2746, Springer-Verlag, pp. 37-53.

2. Keeler, M. [forthcoming, 2005]. "The Philosophical Context of Peirce's Existential Graphs," Cognito, Centro de Estudos do Pragmatismo Filosofia.

3. Keeler, M. and Kloesel, C. [1997]. "PORT: A Testbed Paradigm for Knowledge Processing in the Humanities." In: Lukose, D., Delugach, H., Keeler, M., and Searle, L. (Eds.): Lecture Notes in Artificial Intelligence, Vol. 1257, Springer-Verlag, pp. 505-520.

4. Keeler, M. and Kloesel, C. [1997]. "Communication, Semiotic Continuity, and the Margins of the Peircean Text." In David Greetham (ed.), Margins of the Text. Ann Arbor: University of Michigan Press.

5. Peirce, C. S. [1982-97]. Writings of Charles S. Peirce: A Chronological Edition. Six volumes. Edited by Christian J.W. Kloesel et al. Bloomington: Indiana University Press (see the Peirce Edition Project $<\mathrm{http}$ ://www.iupui.edu/ peirce $>$ ).

6. Robin, R. S. [1967]. Annotated Catalogue of the Papers of Charles S. Peirce. Amherst: University of Massachusetts Press.

7. Puder, A. and Römer, K. [1997]. "Generic Trading Service in Telecommunication Platforms." In: Lukose, D., Delugach, H., Keeler, M., and Searle, L. (Eds.): Lecture Notes in Artificial Intelligence, Vol. 1257, Springer-Verlag, pp. 551-565.

8. Ganter, B. and Wille, R. [1999]. Formal Concept Analysis: Mathematical Foundations. Berlin Heildelberg New York : Springer-Verlag.

9. Priss, U. and Old, L. J. [2004]. "Modelling Lexical Databases with Formal Concept Analysis." Journal of Universal Computer Science, Vol 10: 8, pp. 967-984.

10. de Moor, A. [2004]. "Improving the Testbed Development Process in Collaboratories." In: Wolff, K.E., Pfeiffer, H.D. and Delugach, H.S. (Eds.): Lecture Notes in Artificial Intelligence, Vol. 3127, Springer-Verlag, pp. 261-274.

11. Sowa, J.F. and Majumdar, A.K. [2003]. "Analogic Reasoning." In: de Moor, A., Lex, W., and Ganter, B. (Eds.): Lecture Notes in Artificial Intelligence, Vol. 2746, SpringerVerlag, pp.16-36.

12. Dau, F. [2004]. "Types and Tokens for Logic with Diagrams." In: Wolff, K.E., Pfeiffer, H.D. and Delugach, H.S. (Eds.): Lecture Notes in Artificial Intelligence, Vol. 3127, Springer-Verlag, pp. 62-93.

13. Staat, W. [1993]. "On Abduction, Deduction, Induction, and the Categories," Transactions of the Charles S. Peirce Society, Vol. XXIX, No. 2, pp. 225-237.

14. Keeler, M. [2004]. "Using Brandom's Framework to Do Peirce's Normative Science." In: Wolff, K.E., Pfeiffer, H.D. and Delugach, H.S. (Eds.): Lecture Notes in Artificial Intelligence, Vol. 3127, Springer-Verlag, pp. 37-53.

15. Brandom, R. [2000]. Articulating Reasons: An Introduction to Inferentialism. Cambridge, MA: Harvard University Press.

16. de Moor, A., Keeler, M. and Richmond, G. [2002]. "Towards a Pragmatic Web." In: Priss, U., Corbett, D. and Angelova, G. (Eds.): Lecture Notes in Artificial Intelligence, Vol. 2393, Springer-Verlag, pp. 235-249. 
17. Wille, R. [2003]. "Conceptual Contents as Information-Basics for Contextual Judgment Logic. In: de Moor, A., Lex, W., and Ganter, B. (Eds.): Lecture Notes in Artificial Intelligence, Vol. 2746, Springer-Verlag, pp. 1-15.

18. Parker, Kelly A. [2003]. "Reconstructing the Normative Sciences." Cognito, Centro de Estudos do Pragmatismo Filosofia, Vol. 4, no. 1, pp. 27-45.

19. Martin, P. [1997]. "The webKB set of tools: A common scheme for shared www, annotations, shared knowledge bases and information retrieval." In: Lukose, D., Delugach, H., Keeler, M., and Searle, L. (Eds.): Lecture Notes in Artificial Intelligence, Vol. 1257, Springer-Verlag, pp. 585-588.

20. Sowa, J.F. [2002]. "Architectures for Intelligent Systems." In: Special Issue on Artificial Intelligence of IBM Systems Journal, Vol. 41, pp. 331-349.

21. Pfeiffer, H.D. [2004]. "An Exportable CGIF Module from the CP Environment: A Pragmatic Approach." In: Wolff, K.E., Pfeiffer, H.D. and Delugach, H.S. (Eds.): Lecture Notes in Artificial Intelligence, Vol. 3127, Springer-Verlag, pp. 319-332. 